\title{
Design of a rule-based monetary policy in a Central Bank Digital Currency system
}

\author{
Jacob WIJNGAARD, University of Groningen, Nederland \\ Kees VAN HEE, Eindhoven University of Technology, Nederland
}

Received: 23.06.2021, Revised: 10.10.2021, Accepted: 25.10..2021

doi: http://dx.doi.org/10.29015/cerem.928

\begin{abstract}
Aim: This paper presupposes a purely Central Bank Digital Currency (CBDC) based system. Its aim is to describe how such a system facilitates complete new possibilities to design a suitable monetary policy. More specifically, the purpose is to show that the available monetary tools can be used to design a rulebased monetary policy that guarantees stability of purchasing power and interest rates.
\end{abstract}

Research methods: The paper is design oriented. It describes how the monetary system could function The important monetary variables are defined and their relationship is described. To illustrate these variables and their relationship, simulation results of their behavior are added.

Conclusions: It is shown that it is indeed possible to design a monetary policy that is rule based and guarantees stability of purchasing power and interest rates. Crucial elements in the design are linking the balances of the CBDC-accounts to a proxy of the domestic product and replacing the use of government bonds by allowing the government to borrow from the Central Bank and giving households and businesses the opportunity to open a savings account at the Central Bank.

Originality: The approach is completely new. It is the result of rethinking the possibilities of a complete transition of bank money to CBDC.

Implications: The paper shows that a more absolute transition to the use of CBDC makes it possible to establish a clearer and more stable monetary practice, and that it is necessary therefore to revise monetary theory.

Keywords: Design, CBDC, Rule-based, Monetary policy, Inflation correction, Domestic product proxy JEL: E42, E43, E52, E58, E63.

Correspondence address: Jacob WIJNGAARD, Professor emeritus, Operations, University of Groningen, Nederland. E-mail: j.wijngaard@rug.nl. Kees VAN HEE, Professor emeritus, Computer Science, Eindhoven University of Technology, Nederland. E-mail: k.m.v.hee@tue.nl 


\section{Introduction}

The current monetary system is a two-tiered system. The Central bank (CB) issues base money, including cash and bank reserves. That is the first tier. The commercial banks issue claims on base money (e.g. demand deposits). That is the second tier. As of recently, the possibility to give more parties access to base money is seriously considered. It is called Central Bank Digital Currency (CBDC). In its most extreme form it makes the money creation function of the commercial banks superfluous and leads to a one-tiered system: all economic actors pay each other with base money. This extreme option has not much support yet among bankers, monetary economists and politicians, but it is worth to explore the possibilities, also the possibilities with respect to monetary policy.

The goal of monetary policy is to keep the purchasing power of the currency stable. In the current system this appears to be difficult. The main tool of the $\mathrm{CB}$ is to control the rate at which the banks can borrow base money from the $\mathrm{CB}$. This tool appears to be ineffective now. To keep control the $\mathrm{CB}$ has to switch to some form of Quantitative Easing $(\mathrm{QE})$ and that is not very effective either. And the lack of transparency and stability in the monetary policy leads in itself to dynamics. A transfer to a CBDC based system gives the opportunity to redesign the monetary policy. In a companioning paper (Van Hee, Wijngaard 2021) we describe how such a CBDC based system can be organized. In this paper we focus on the monetary policy.

Section 2 discusses why it is necessary to redesign the system and gives a short description of the proposals developed in the companioning paper (Van Hee, Wijngaard 2021). Section 3 explores the tools that are available in a CBDC based system to develop a monetary policy. In sections 4-7, we show how these tools can be used to design an attractive monetary policy. Important elements are: linking the current accounts to a proxy of the domestic product and replacing the use of government bonds by the use of specific savings accounts. This results in a rule based monetary policy with automatic inflation control and stable risk-free interest rates. Section 8 gives conclusions and suggestions for further research. 


\section{Towards a new monetary system}

The current monetary system is an organically grown system. Its weaknesses became apparent by way of the financial crisis of 2008 and have been described sufficiently broad (e.g. Roubini, Mihm 2010; Admati, Hellwig 2013). We propose to design a new monetary system.

Today we have two forms of money, cash (coins and bank notes) and demand deposits (balances on current bank accounts). Cash is part of the so called base money (see Ryan-Collins et al. 2011). The rest of the base money is invisible for normal economic actors: households and businesses. It consists of the reserves of (commercial) banks and the government, at the CB. A demand deposit is (only) a claim on base money. Such claims are generally accepted and form the main part of the available money. Banks are able to create these claims more or less freely. Note that these claims are digital, so, it is a form of digital money. Today ca $95 \%$ of our money is claims on base money and if all economic actors would cashing in their claims, this would be a disaster because banks don't have the base money at hand. Bank credits are a strange form of money indeed. Nevertheless, from 1971, after the abolition of the Bretton Woods agreement, it has functioned well for a while. By adapting the interest rate for reserves, the availability of credit was controlled, and through this the whole economy. And especially during the period 1985-2005, the system appeared to be really "under control". That is why that period is called "the great moderation". In between, however, there are serious doubts. Banks have played an important role in the emergence and proliferation of the financial crisis. The American mortgage market was the biggest culprit, but the lack of transparency and the sale of too complex financial products contributed as well (see Roubini, Mihm 2010). There are general rules with respect to reserves and liquidity (Basel I, II and III). But the position of a bank is judged afterwards and the judgement of the different categories of assets and the validity of the rules are not always clear (see Admati, Hellwig 2013). This implies that the banks have in fact a (too) large freedom with respect to the creation of money, because the claims are rarely cashed and all checks and balances are directed to a smooth continuation of the system. This made it easy for them to participate in these risky products and spread the problems in that way. 
This is a fundamental weakness in the existing system. It is directly connected with the two-tiered character of the system, that we use bank money, claims on base money, while we are not very interested in the use of cash, the only form of base money accessible to us. It is time to widen the role of base money (or CBDC) and have that as our primary form of money, the only legal tender. So, the CB creates the money and the main role of the banks is to intermediate between lenders and borrowers. Our proposal for such a new system is described in (Van Hee, Wijngaard 2021). It is inspired by the proposals of the Positive Money movement (Jackson, Dyson 2012) in the UK (see Huber 2017 for an overview of the positive money movement), but differs in some respects and is more explicit in its design, especially regarding privacy and security. Here we sketch the main elements. It is completely different from the developments considered by the Central Banks in e.g. Sweden and the eurozone, where one explores the possibilities to combine the introduction of CBDC with continuation of the current system (see Sveriges Riksbank 2017; ECB 2020).

- Actors have $C B D C$-accounts, as many as they like. An account is an abstract object that is "owned" by the actor and that is stored on the hardware of the actor or in a cloud of a service provider operating on behalf of the actor. The account has several properties such as a unique account identity and the identity of the actor. But the most essential property of the account is the balance, i.e. the amount of currency on the account. This balance is at least zero, so it is never negative.

- An exception is made for banks. If they have a license of the $\mathrm{CB}$, they are allowed to borrow from the central bank. In order to do this, there are besides the normal accounts at the $\mathrm{CB}$ also $C$-accounts (credit accounts), with a balance $<=0$. To borrow from the $\mathrm{CB}$, a bank can just transfer some money from her $\mathrm{C}$-account to another account, making the balance on the $\mathrm{C}$-account more negative.

- The (central) government has also such a $\mathrm{C}$-account, to be able to borrow from the CB.

- All other actors may borrow money from other actors, in particular from banks, but not from the CB. 
- Actors may use one of their accounts as a bank savings account. That means that they give a bank access to it and allow the bank to use the balance for loans to other actors. Of course, they have to do so under certain conditions (interest, term, ...). Note that as long as the money is on the savings account it is not lended yet. As soon as it is lended to another actor, the money moves from the savings account to the account of the borrower. The bank administers this process.

- There is a public database as part of the CBDC-system and in that database there is some data of the accounts, but neither the balance itself nor the transactions themselves. What is stored is a digital fingerprint of the balance account. This is done by applying a one-way function or hash function to the account record and store this value. It can be used to verify the authenticity of an account record presented by the actor for updating, by applying this one way function to the current account record and compare the outcome with the stored value. The database is called "public" because all actors have access to it. We avoid the term "central" database because it will be a distributed database, i.e. a network of databases, but all under control of the CB. This database could be constructed as a blockchain, although we don't see any particular advantage of that.

- There is a clearing/settlement function in the CBDC-system. Here the most basic payment action is performed: the increase of the balance of the acquiring actor and the decrease of the balance of the paying actor. And there is a secure transmission system to send messages between actors and the $\mathrm{CB}$, including the authentication of the sender and the integrity and confidentiality of the message.

- It is to expect that service providers are going to develop different kinds of services, to integrate the payments with the financial and management control of the actors. Since all actors use the same CBDC-system, this is a very open, competitive world.

The $\mathrm{CB}$ can be seen as a trusted third party for payments between two actors. But this does not mean that the $\mathrm{CB}$ keeps record of the values of balances of the actors. 
We only let the CB keep a fingerprint of the balance and maybe also of the transactions.

In this paper we focus on the monetary policy that can be applied in combination with such a CBDC-system. If necessary it is possible to create off-line payment possibilities and we assume therefore that physical cash is no longer used. There will be a transition period where $\mathrm{CB}$-cash exists in parallel to $\mathrm{CBDC}$, however we just consider the final state with only $C B D C$ here.

\section{Exploring the tools for a monetary policy}

Here we consider the case of one country with one CBDC-system. In most countries the main goal of the monetary policy is to control the price level. Until recently, the aim of the ECB was to realize an inflation of $2 \%$ or a little less. This is a very narrow goal and indeed difficult to realize. Since the summer of 2021, the goal was changed into "an average inflation of $2 \%$ ". This gives more freedom to deviate from the $2 \%$ and it may also help in realizing that the public keeps expecting an inflation of $2 \%$ even if that inflation is now lower. This inflation target protects the purchasing power of the public. We are going to design a different system to protect the purchasing power. But we want more. We should not be happy with only stability of the purchasing power of consumer goods, we also want to realize stability of the yield of saving and investing and, to keep it symmetric, of the cost of borrowing. Risks cannot be controlled, but it may be possible to control the risk-free interest rate. This is related to taking care of sufficient credit possibilities, sufficient for a prospering economy, a goal that is explicitly included in e.g. the monetary goals for the US ${ }^{1}$. We use the wider goal of a stable purchasing power in this broad sense.

In case of such a CBDC-system there are many tools available to realize this goal. $\mathrm{CB}$ and government have both an important role. The CB makes the money available and determines the conditions. The government is important through its fiscal policy and because of the way deficits are financed.

\footnotetext{
${ }^{1}$ See the website of the FED: https://www.federalreserve.gov/faqs/what-economic-goals-does-federalreserve-seek-to-achieve-through-monetary-policy.htm.
} 
1) Interest rate on reserves. Currently, the main tool for the $\mathrm{CB}$ is the interest rate for the reserves of the banks. In the new system, all actors have CBDC (which is base money) and there is no physical cash anymore. So, the interest tool is richer now. It is not restricted to values $>=0$ ("breaking the lower bound"2) and it is possible of course to distinguish between different types of actors and different conditions of availability. Note that a negative interest on CBDC can also be interpreted as a tax on having CBDC, a liquidity tax.

i) Banks can borrow from the $C B$. The interest rate on such loans is an important tool.

ii) Households and businesses can be allowed to start a savings account with the $C B$, for longer term deposits. The interest rate on such savings accounts is also an important tool.

2) Indexing account balances. It is possible to index the account balances to the price level, to keep the purchasing power of the account balance constant. This necessitates a monitoring process that keeps account of the changes in the price level $p(t)$. Each account can only be adapted at transaction moments, because the $\mathrm{CB}$ only keeps the fingerprints of the accounts and their balances. When indexed, the balance is multiplied with $p(t) / p\left(t_{l}\right)$, with $t_{l}$ the last time the account was updated $^{3}$. One step further is to link the account balances to some proxy of the nominal domestic product (DP-linking), instead of to the price level. All payments from households to businesses during the last year could serve as such a proxy. Since all payments or at least almost all payments are in CBDC it is possible to monitor these payments real time by labelling the transactions of the accounts (household accounts and business accounts) by the type of transaction.

3) Transaction tax. The way the government is financed is an important factor in the realization of stability. We assume that the government is at least partly financed by taxation. Changes in the value added tax (VAT) have also influence on the price stability. An increase in the price level could be compensated for by a reduction in the VAT. Changes in the deductibility of interest on mortgages

\footnotetext{
${ }^{2}$ See Buiter (2009) for a general treatment of this issue of "breaking the lower bound".

${ }^{3}$ Bordo and Levin (2017) mention this possibility, but choose for the interest tool to keep the price level stable.
} 
influence the credit possibilities. It is important to distinguish these taxes from the liquidity tax, the tax on the account balance that is mentioned in point 1).

4) Monetary financing of government deficits. Government deficits can be financed monetarily by borrowing from the $\mathrm{CB}$. In our system, the interest rate for such loans is by definition equal to 0 , since the $\mathrm{CB}$ is owned by the government. Note that this is also stressed in the Modern Monetary Theory (MMT) ${ }^{4}$.

5) Government activity on the financial market. It is also possible to let the government be active on the financial market by selling different kinds of bonds. By using the dynamics of the financial market, the government may be able to reduce the cost of a deficit, but these activities contribute also to these dynamics. It is clear that designing a good monetary policy is a multi-dimensional decision problem. And the use of government tools and CB tools have to be determined in combination. Of course it is necessary to structure it. We propose to structure it towards rules and discretion. What are the rules? Who (which institution) monitors the rules and decides whether and how they have to be adapted. Where are we going to require discretion? An important question here is whether and how to involve politics. Somehow in this structure the role of the $\mathrm{CB}$ and the role of the government have to become clear.

The next four sections are devoted to the description of one specific possible design of the monetary policy, where we use DP-linking and a government that borrows only from the CB. The DP-linking is described in section 4, together with a simplified version of the policy. The complete policy is described in section 5 . The policy is almost completely rule-based. In section 6 , we discuss the limits of this rulebased character of the policy. We also discuss how to organize the necessary decision making: the rules, the tuning of the parameters, the space for discretion and the bargaining. In section 7, we sketch how such a policy could look like in the eurozone, a case of more countries with one CBDC-system.

\footnotetext{
${ }^{4}$ See Kelton (2020) for a general description of MMT. An important element in MMT is the structural role of the government in monetary policy and the acceptance of government deficits in stimulating the economy.
} 


\section{Linking the accounts to a proxy of the domestic product}

This section explains how to link the content of these accounts to a DP-proxy. The aim of this is to secure the purchasing power of the accounts. We are not going to secure the purchasing power of one currency unit, but the purchasing power of the total balance of each of the accounts.

First we will formulate this linking for an arbitrary macro-economic (aggregate) variable that can be monitored real time. Let $A(\cdot)$ be such a continuously available variable. Linking the current accounts to $A(\cdot)$ means that the balance of each current account is adjusted to $A(\cdot)$ each time a transaction takes place. Only at such moments the CBDC-system has access to the accounts. Suppose the accounts $i$ and $j$ are involved in a transaction that takes place at time $t$. Let $C_{i}\left({ }^{\cdot}\right)$ and $C_{j}(\cdot)$ be the balances of these accounts. Just before the execution of the transaction, the balances are reset in the following way5:

$C_{i}(t):=\frac{A(t)}{A\left(t-\varepsilon_{i}\right)} \cdot C_{i}(t)$

with $t-\varepsilon_{i}$ the time (in years) of the previous transaction with respect to account $i$, and a corresponding update for account $j$. The update is executed by the CBDCsystem, together with the execution of the payment.

If the variable $A(\cdot)$ represents a stable economic value and reflects broad price changes, the linking procedure helps to secure the purchasing power of the current accounts. But it is important that it is continuously available. We propose to use a proxy of the domestic product, the total sum of all payments by households, for (new) real goods and services during the past year. We call this variable $D(\cdot)$. To keep track of $D(\cdot)$, it is necessary to label the transactions. In Appendix 1 we discuss the definition of this proxy and the way of labelling in more detail.

With DP-linking the content of an account follows price increases as well as productivity increases. This may make it attractive for investors to put money on an account and just leave it there, enjoying the general productivity increases as return

5 := stands for "going to be equal to". 
on investment on this account. This necessitates to "tax" the linked account. Instead of the DP-proxy, $D(t)$, the taxed DP-proxy, $e^{-\tau t} \cdot D(t)^{6}$, is used. Equation (1) is replaced then by:

$C_{i}(t):=e^{-\tau \varepsilon_{i}} \frac{D(t)}{D\left(t-\varepsilon_{i}\right)} \cdot C_{i}(t)$

The liquidity tax $\tau$ (per year) has to be sufficiently large to form an effective incentive to spend money instead of just keeping it.

We have to explain in more detail why this (liquidity) tax is necessary. The variable $D(t)$ does not include any intermediate economic activity: the build-up of inventories, the production of intermediate products and of production equipment, the development of production processes and of know-how, etcetera. This reservoir of investments is going to contribute in the future to the value of $D(\cdot)$. Part of these investments is privately owned. The ownership can be direct or via a share or a loan. This private part of the reservoir may be expected to be stable. So the value of these private investments grows with $D(\cdot)$. Let $W(t)$ be the value of these investments at time $t$ and let $\Delta W(t)=W(t+1)-W(t)$. The reservoir is owned by a relatively small part of the population. That implies that only little of the yield is consumed. Let $\omega$ be the yield per unit of value and $c$ the consumption rate and let $W_{n}(t)$ be the contribution of new investors. Then:

$$
\Delta W(t)=(1-c) \cdot \omega \cdot W(t)+W_{n}(t)
$$

The fraction $c$ is small and $W_{n}(t)$ is also small compared to $W(t)^{7}$. That means that the growth of $W(\cdot)$ is rather close to $\omega$. So, the average yield on risky investments is rather close to the growth of $D(\cdot)$. That means that without liquidity tax it may become attractive not to spend the money. Just keeping it on the account gives a risk free growth that is close to the average yield of investing it in another way.

\footnotetext{
${ }^{6}$ The function $e^{-\tau t}$ is the solution of the equation $\frac{d f}{d t}=-\tau f(t)$, so the result of applying a proportional tax $\tau$ to $f(t)$.

${ }^{7}$ See Piketty (2014), Chapter 5.
} 
By choosing $\tau=g+0.02$, with $g$ the growth rate of the DP, we realize a yearly reduction of the purchasing power of $2 \%$. But a smaller $\tau$ may be sufficient. In the current system, a sufficiently large inflation is necessary to keep the monetary policy effective (see Bordo, Levin 2017). In our system it is sufficient to choose $\tau$ so large that hoarding the money is not attractive.

The purchasing power is controlled by linking the account balances to a taxed DPproxy. One may worry that that may lead to more instability of the prices. In Appendix 2 we give the results of a simulation experiment with respect to this point. It shows that linking the account balances may lead to some extra price instability. This does not lead to extra instability of the purchasing power, however. It may nevertheless be attractive to seek ways to stabilize the prices. But that is not part of the monetary policy in our view. The monetary policy controls the purchasing power, not the prices.

The taxation reduces the total amount of money. It is easy to compensate this reduction by adding the same amount of money to one of the accounts of the (central) government. We call this the monetary tax account. This leads to a very simple monetary policy: the account balances are linked to $e^{-\tau t} \cdot D(t)$, the CB transfers immediately what is taxed to the monetary tax account of the government, the government takes care of its own deficits by borrowing on the financial market and the banks have to use superfluous money of other actors to perform their crediting function. This policy is going to be a reference point in the further design of the monetary policy. Let $M(t)$ be the amount of money at time t. Since $M(t)$ remains in line with $D(t)$ and since $M(t) \cdot V=D(t)$, with $\mathrm{V}$ the velocity of circulation of the money, this policy keeps this velocity constant ${ }^{8}$.

The aim of this taxed DP-linking is to make further inflation control superfluous. The DP-proxy forms a stable and real basis for the value of the current accounts. There is a time delay however. It is possible that the current prices increase faster than the prices of a year ago and the average price over the last year. In principle it is possible to work with the DP over a shorter period. But seasonality is so significant that it is difficult to construct a stable DP-proxy then. So, we have to accept this time delay.

\footnotetext{
${ }^{8}$ This is the Fisher equation, with the right hand side written in another way.
} 
If the (nominal) growth of $D(\cdot)$ is smaller than $\tau$, the taxed DP-proxy is decreasing and the balance is also decreasing. It will take time for households to get used to this and it may anyway be inconvenient to apply it also for the household accounts that are used for daily shopping. It may be useful therefore to give households the opportunity to exclude (some of) their accounts from the linking, under the condition that the balance remains below a certain limit.

Once we have this DP-linkage for the account balances, it becomes easy to express the balance of an account as a fraction of the DP. Suppose the DP is about $10^{12}$ currency units. Then one could speak of 1 pico- $D P$ instead of 1 unit. If an account with a balance of 1 pico is not used for transactions, the balance after a year is equal to $e^{-\tau} \cdot 1$ (pico), while the balance in currency units is more complex because it depends also on changes in the (nominal) DP.

It is straightforward to formulate loans also in this DP-linked way. We call that pico-loans. A loan of 100 pico for 2 year, with an interest of $1 \%$ implies that one has to pay each year 1 pico interest and one has to pay back 100 pico at the end of the year $2^{9}$. Having all loans and bonds in this DP-linked form leads to a situation where all assets and liabilities are expressed in pico. The DP-proxy forms a stable and real basis for the financial assets. Transactions with respect to real goods and services remain in currency units. This is the basis for the (taxed) DP-linking. The continuously available DP-proxy serves as the exchange rate.

\section{Designing the monetary policy}

In this section we describe how the simple, reference monetary policy described in the previous section can be improved. We keep the linking to a (taxed) DP-proxy, $D(t)$. This guarantees the purchasing power of the account balances. In the simple policy of Section 4, the total amount of CBDC is kept equal to a constant fraction of $D(t)$, say $\mu \cdot D(t)$ by adding the liquidity tax immediately to the monetary tax account

\footnotetext{
9 Compare this with the already existing inflation indexed bonds. See the Wikipedia page: https://en.wikipedia.org/wiki/Inflation-indexed bond. Kamstra, Shiller (2008) suggest to go a step further and link the bonds to the GDP. They call this trills (one-trillionth of Canada's GDP). This is worked out and related to pension building.
} 
of the government. Possible deficits of the government have to be financed by borrowing at the financial market and the banks are not allowed to borrow from the CB. This monetary system has the following drawbacks:

a) The government contributes to the dynamics of the financial market and makes itself dependent of it, instead of stabilizing it.

b) Banks are inflexible with respect to their credit supplying function. Households and businesses may make too little money available.

c) It is unclear how to determine the right amount of CBDC. Too little CBDC may hinder productive investments, too much CBDC may lead to speculation and instability of the financial markets.

d) There are no tools to realize the stability of the risk-free interest rate.

We will discuss how to overcome these drawbacks and develop additional rules.

The first important point is to accept that the CB is government-owned. So, giving the $\mathrm{CB}$ the opportunity to create more money (CBDC) and then adding this extra money to the monetary tax account of the government account is equivalent with not changing the amount of money and allowing the government to borrow freely (interest $=0$ ) from the $\mathrm{CB}$. We choose this latter option: the government may borrow freely from the $\mathrm{CB}$ and the money creation function of the $\mathrm{CB}$ is restricted to keeping the balances linked to $D(t)$ and adding the liquidity tax to the monetary tax account of the government. In this respect our approach is getting close to the Modern Monetary Theory (MMT) (see Kelton 2020). That means that we have to deal with the doublefunction of government expenses. In the first place to take care that the essential functions to support the society can be performed and in the second place that the monetary function of providing sufficient liquidity, credit supply and general monetary stability can be performed. The role of the CB is to monitor and safeguard this second function, but, of course, it has only very partial control over the government expenses.

To prevent that extra government expenses lead to too much CBDC in the economy, we introduce $C B$ savings accounts. These accounts are made attractive for actors with superfluous CBDC. They have to deposit the money for a longer term (e.g. more than a year), but pay less liquidity tax, $\sigma<\tau$, instead of $\tau$. This reduces the amount of (liquid) CBDC in the economy immediately, but can also be used as a signal 
that there is too much $C B D C$. We assume that really productive investments have a yield $>=0$ (see section 4). So, if we keep $\sigma>0$, a large total balance on these savings accounts signifies that there are no really productive investments available anymore.

To guarantee sufficient credit supply, we allow banks to borrow CBDC from the $\mathrm{CB}$ by transferring money from their $\mathrm{C}$-account to another account, making the balance on the $\mathrm{C}$-account (further) negative ${ }^{10}$. This increases the amount of $C B D C$ in the economy immediately, but the total amount that is borrowed can also be used a signal that there is too less $C B D C$ in the economy. The interest paid by the banks to the $\mathrm{CB}$ is transferred immediately to an account of the government, just like the liquidity tax.

These two signals can be used to control the amount of $C B D C$ in the economy. Here we differ from the MMT approach. In MMT the main signal for too much CBDC is inflation, indicating a lack of production capacity. Our approach is insensitive for inflation, because of the DP-linking. We presume that the two signals suggested here are more sensitive for the amount of CBDC that is needed in the economy.

The interest $\rho$ that banks have to pay on the loans from the CB determines an upper limit on the interest that has to be paid in the economy for a risk-free investment. The upper limit for the interest to pay on a loan from the (commercial) bank for a risk-free investment is equal to $\rho+a$, with $a$ an allowance for cost and profit of the bank. It is an upper limit, because part of the CBDC a bank has available is from deposits of other actors; the interest the bank pays on these deposits is already attractive for the owners if it is larger than $-\sigma$, because that is what actors receive on a CB savings account. . So, we have to choose $\rho>-\sigma$ to realize that it is attractive for actors to make their superfluous money available to the banks. But by keeping $\rho$ close to $-\sigma$, the variations of the interest rates remain restricted.

A deposit on a CB savings account is more or less comparable with the possession of a long term government bond in the current system (or the reference system of section 4). People use these bonds as a secure savings possibility, as a part of their pensions. A CB savings accounts could give that same opportunity. This should be

\footnotetext{
${ }^{10} \mathrm{~A}$ critique on the Positive Money inspired proposals is that there is lack of credit possibilities (Fontana, Sawyer 2016). See Dyson et al. (2016) for a reaction.
} 
taken into account in interpreting the total balance on the $\mathrm{CB}$ savings accounts as signal for too much CBDC in the economy. Only if the total balance on the savings accounts gets larger than some critical value, it may be interpreted as signal that there is too much CBDC in the system. This critical value is also an important monetary policy parameter. Maybe, it is even possible to make the liquidity tax on a savings account equal to 0 as long as the balance remains below a certain limit or to have separate "pension" accounts without liquidity tax. But these options are not worked out in this paper.

In the rest of this section, we make the just described system more precise with a more formal model. All variables are expressed as fractions of $D(t)$. We distinguish state (or "stock") variables and flow variables. First we introduce the state variables.

1) $E(t)$ is the total amount of CBDC on accounts in the economy at the start of day $t$. The economy consists of households, banks and businesses. Service producing government organizations and local governments are also interpreted as businesses ${ }^{11}$. The $\mathrm{C}$-accounts of the banks are not included here and the $\mathrm{CB}$ savings accounts are also excluded. So, transferring $\mathrm{CBDC}$ to a $\mathrm{CB}$ savings account reduces $E(t)$ and banks borrowing from the $\mathrm{CB}$ increase $E(t)$.

2) $C B(t)$ is the total amount of $C B D C$ that banks have borrowed from the $\mathrm{CB}$ at the start of day $t$.

3) $S(t)$ is the total amount of CBDC on CB savings accounts, at the start of day $t$.

4) The difference $S(t)-C B(t)$ is the net economy savings. It is called $N S(t)$.

5) $G(t)$ is the total amount of CBDC on accounts of the central government (the Caccount not included), at the start of day $t$.

6) $C G(t)$ is the total amount of CBDC borrowed by the central government (through her C-account) at the start of day $t$.

7) Define $N G(t)$ as the net CBDC balance of the government: $N G(t)=G(t)-$ $C G(t)$.

For all state variables $F(\cdot)$ we define $\Delta F(t)=F(t+1)-F(t)$.

\footnotetext{
${ }^{11}$ See Appendix 1 for a more detailed explanation.
} 
Now we describe in more detail what happens during an arbitrary day $t$, the flow variables and the relationships between the variables.

1) The $\mathrm{CB}$ receives the liquidity tax and the interest on the $\mathrm{C}$-accounts of the banks and pays this right away to the government. We call this $C B G(t)$. So:

$C B G(t)=\tau^{\prime} \cdot E(t)+\sigma^{\prime} \cdot S(t)+\rho^{\prime} \cdot C B(t)$

with $\tau^{\prime}=1-e^{-\tau / 365}$ and $\sigma^{\prime}$ and $\rho^{\prime}$ defined in the same way.

2) We define $U(t)$ as the net government payments in day $t$ (the payments minus the received taxes). The contributions through the $\mathrm{CB}(C B G(t))$ are not included here. Together with the previous point, this implies:

$\Delta N G(t)=C B G(t)-U(t)$

3) Changes in $E(t)$ are caused by this government surplus (or deficit) of (5) and by changes in $N S(t)$ :

$\Delta E(t)=E(t)-\Delta N G(t)-\Delta N S(t)$

4) Changes in $N S(t)$ are determined by the economy actors, households, businesses and banks. The "market" so to speak. In case of a perceived shortage of liquidity, $N S(t)$ is increased, in case of a perceived surplus of liquidity, $N S(t)$ is reduced. A simple way to model such a mechanism is to define $E_{R}$ as the perceived requirement and assume for $\Delta N S(t)$ :

$$
\Delta N S(t)=\alpha \cdot\left(E(t)-E_{R}\right)
$$

with $\alpha$ a constant $>0$. Reality is probably more complex. This is just to illustrate the mechanism. If more erratic behavior is thought to be appropriate, it is possible to add a stochastic term to $E_{R}$. Note that the equations (4), (5) and (6) are accounting equations, while this equation (7) tries to model economy behavior. 
5) The net economy savings, $N S(t)$ can be increased in two ways, by increasing the savings $S(t)$ or by reducing the bank loans from the $\mathrm{CB}, C B(t)$. The allocation of $\Delta N S(t)$ to $\mathrm{S}(\mathrm{t})$ and $\mathrm{CB}(\mathrm{t})$ is determined by $\rho, \sigma$ and the importance to keep some risk free savings at the savings accounts with the CB. We could model this allocation mechanism by assuming a lower limit, $S_{N}$ for $S(t)$. This stands for the savings that are required as part of the pensions. The allocation can be modeled then by assigning a positive $\Delta N S(t)$ insofar as it is possible to $C B(t)$ and a negative $\Delta N S(t)$ insofar as it is possible to $S(t)$ (keeping $S(t) \geq S_{N}$ ). This results in:

$$
\begin{aligned}
& C B(t+1)=\max \{0, C B(t)-\Delta N S(t)\} \\
& \text { and } S(t+1)=N S(t+1)+C B(t+1) \quad \text { if } \Delta N S(t) \geq 0 \\
& S(t+1)=\max \left\{S_{N}, S(t)+\Delta N S(t)\right\} \\
& \text { and } C B(t+1)=S(t+1)-N S(t+1)) \quad \text { if } \Delta N S(t)<0
\end{aligned}
$$

We assume here that the limit $S_{N}$ remains constant over time. It results in a situation where $S(t)>S_{N}$ and $C B(t)>0$ do not occur simultaneously. To make it more realistic one could add a stochastic term to $S_{N}$, making it vary over time ${ }^{12}$.

To take the signals for too much CBDC and for too little CBDC seriously, they have to be used by the government to control the government surplus/deficit: $U(t)>$ $C B G(t)$ or $\Delta N G(t)<0$, a government deficit, leads to more CBDC in the economy, $U(t)<C B G(t)$ or $\Delta N G(t)>0$, a government surplus leads to less CBDC. In case of a completely exogenous, autonomous $U(t)$, the system is not well controlled. If $N S(t)<S_{N}$, households can only realize the necessary risk-free savings by increasing $C B(t)$. So, the government has to create a deficit to correct this. If $N S(t)>S_{N}$, there is more than enough to facilitate the required risk-free savings. So, the government has to create a surplus to correct this. Problem is that $S_{N}$ is not precisely known and may also be varying. One could work with an upper estimate $S_{U}$ of $S_{N}$ and a lower estimate $S_{L}$ of $S_{N}$ and apply the following rule:

\footnotetext{
12 That necessitates to adapt formula's $(8 \mathrm{a} / \mathrm{b})$ a little.
} 
$\Delta N G(t) \leq \gamma \cdot\left(N S(t)-S_{L}\right), \quad$ if $N S(t) \leq S_{L}$

$\Delta N G(t) \geq \gamma \cdot\left(N S(t)-S_{U}\right), \quad$ if $N S(t) \geq S_{U}$

And no restrictions if $S_{L}<N S(t)<S_{U}$.

A way to explore these rules is to simulate their effect for the case where the government surplus is equal to some stochastic variable with mean 0 . The stochastic variable is truncated then by the rules (9a) and (9b). If we combine this with expression (7), the behavior of $E(t)$ and $N S(t)$ is completely determined. We will show some simulation results. For the parameters $\alpha, \gamma$ we assume $\alpha=\gamma=0.1$. The perceived requirement $E_{R}$ is assumed to be equal to $0.8+e$, with $e$ uniformly distributed on $[-0.1,+0.1]$. The stochastic variable for the government surplus is uniformly distributed on $[-0.05,+0.05]$. For the bounds in $(9 \mathrm{a} / \mathrm{b})$ we choose $S_{L}=0.8$, $S_{U}=1.2$. Figure 1 gives characteristic results (just one realization of the two stochastic variables) for 400 periods. Think of the periods being equal to 0.1 year. The course of $N S(t)$ being given, the allocation procedure of equations $(8 \mathrm{a} / \mathrm{b})$ determines then the course of $S(t)$ and $C B(t)$. We use here $S_{N}=1$. See fgure 2 for the results. In figure 3 we see the effect of adding variability to $S_{N}$. We add a uniformly distributed stochastic variable $([-0.1,+0.1])$. We lose the property that $S(t)>S_{N}$ and $C B(t)>0$ do not occur simultaneously. But the total effect is small. That suggests that the system is insensitive for the precise allocation of $\Delta N S(t)$ over $S(t)$ and $C B(t)$. 
Figure 1. Characteristic simulation results for $E(t)$ and $N S(t)$.

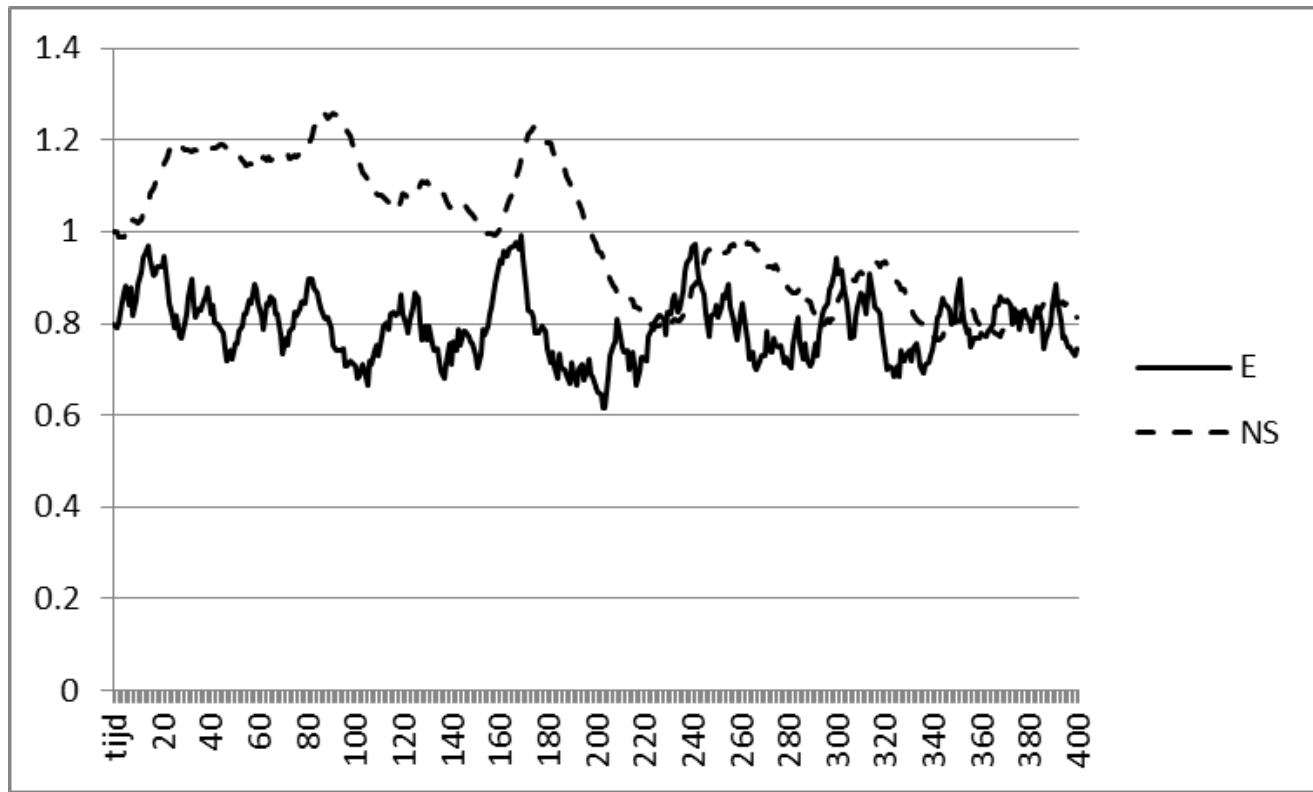

Source: authors' own elaboration

Figure 2. $N S(t)$ split into $S(t)$ and $C B(t)$

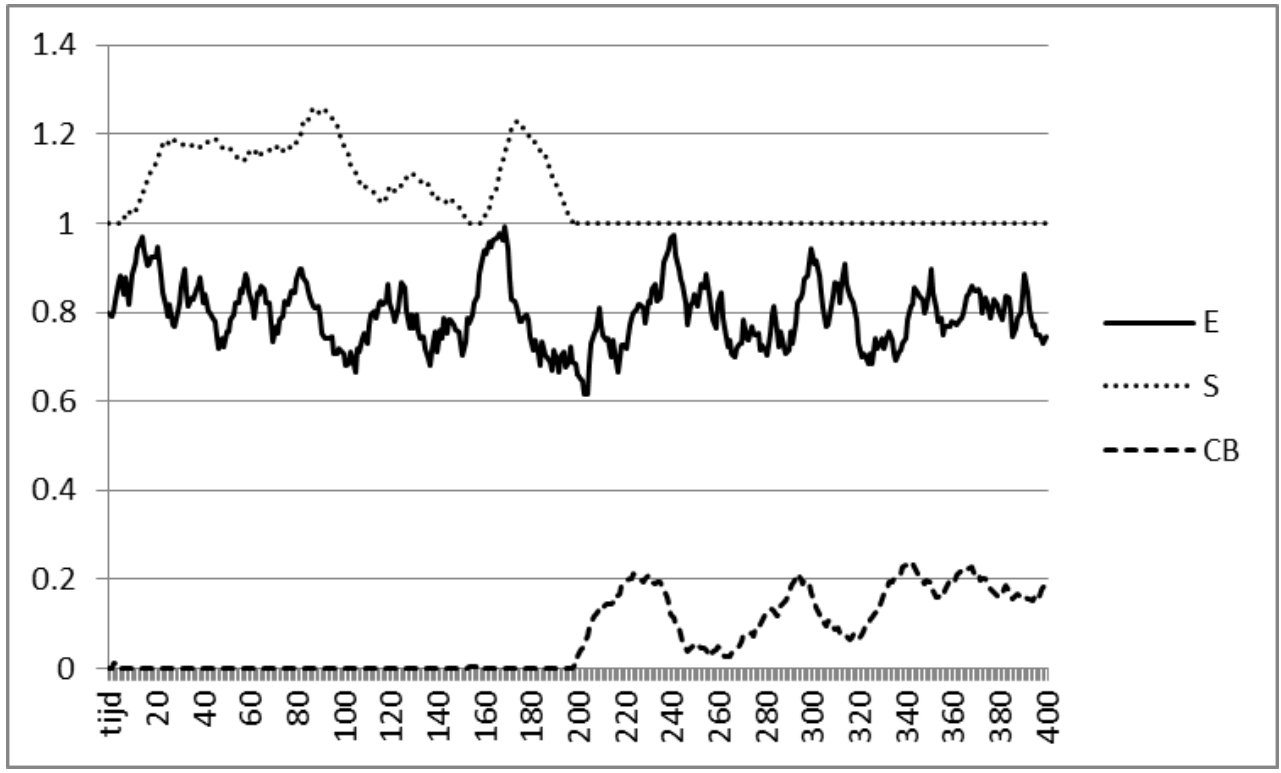

Source: authors' own elaboration 
Figure 3. $N S(t)$ split into $S(t)$ and $C B(t), S_{N}$ varies stochastically

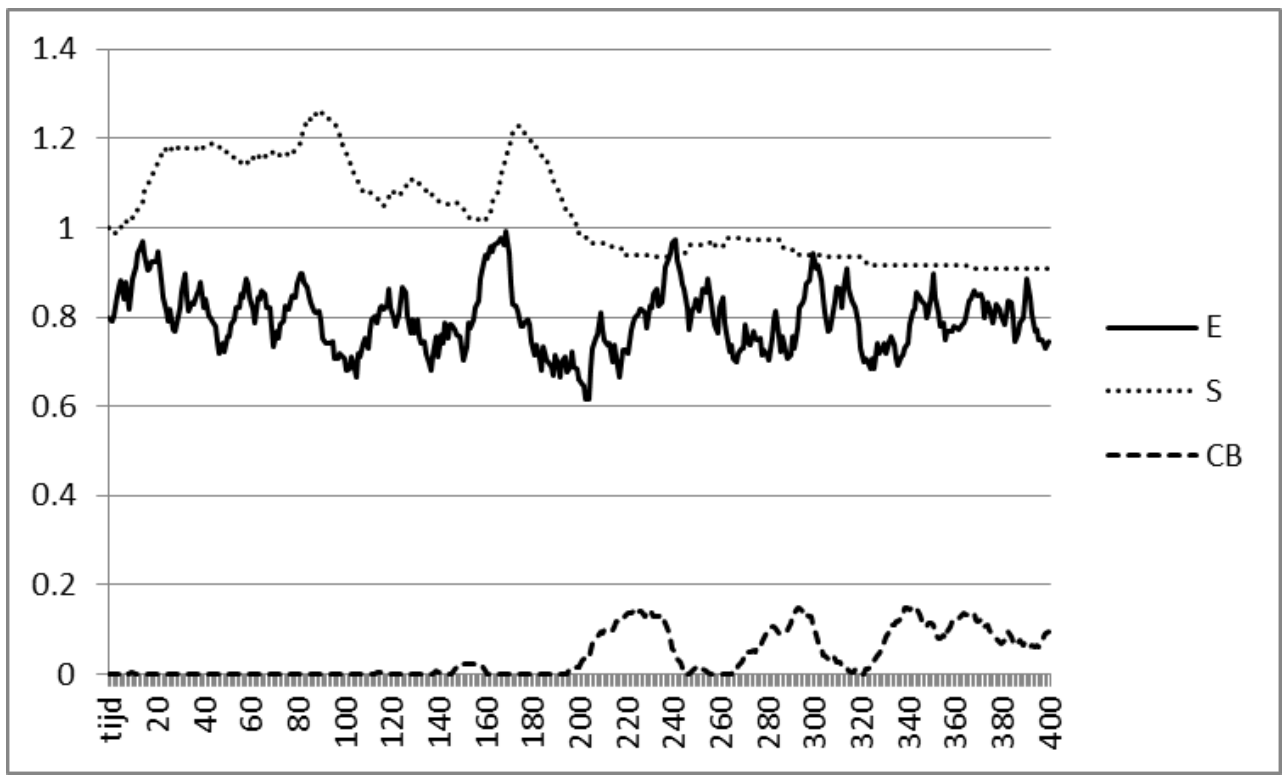

Source: authors' own elaboration

The example is arbitrary. We do not try to give a precise and realistic model of what is going to happen in reality. The simulations are just meant to show how the mechanisms described in equations $(7),(8 \mathrm{a} / \mathrm{b})$ and $(9 \mathrm{a} / \mathrm{b})$ work, how the behavior of the market (equations (7) and ( $8 \mathrm{a} / \mathrm{b})$ can be stabilized by rules for the behavior of the government (equations $(9 \mathrm{a} / \mathrm{b}))$.

The total monetary system consists of the following elements:

a) The precise definition of the DP-proxy, $D(t)$.

b) The liquidity tax $\tau$.

c) The limit $H$ on the balances of the household accounts that are free of liquidity tax and the precise conditions for such accounts.

d) The reduced liquidity tax $\sigma$, and the precise conditions for a $\mathrm{CB}$ savings account.

e) The interest rate $\rho$ on a loan from the $\mathrm{CB}$, and the precise conditions for such a loan.

f) Guidelines for the feedback on $N S(t)$, including a way to deal with the critical limit $S_{N}$ for the amount of risk-free savings that is considered to be adequate. 
The variable $D(t)$ and the parameters $\tau, \rho, \sigma$ can be fixed, except during a first learning period. The parameter $S_{N}$ varies with the demographic situation and it is well possible to develop rules about how it has to vary. The feedback mechanism is most complicated, because this interferes directly with the government expenses.

The independence of the CB from the government that is suggested with respect to the current monetary system is a fiction. The feedback that is necessary, namely of $\Delta N G(t)$ on $N S(t)$, complicates the monetary system, but it is better to accept it. That means that when discussing the government surplus or deficit, it is also necessary to consider the monetary situation. Maybe it is not possible to develop a fixed rule that links the government expenses completely with (only) $N S(t)$. The development of the prices and the functioning of the financial markets are also relevant here. But we expect that $N S(t)$ is an important signal and the necessity of feedback on it has to be taken seriously.

\section{Rules versus discretion or rules \& discretion. Near-money and extreme disturbances}

The monetary system developed in the previous sections is aimed to be rulebased. That is a system where the decisions to be taken are predetermined by a public and transparent rule. That means in this case that the definition of $D(\cdot)$ has to be fixed and its definition and value have to be publicly available, that the parameters $\tau, \rho, \sigma$ have to be fixed, that there is a rule determining the parameter $S_{N}$ and, finally, that there is a rule for the guidelines with respect to the government expenses that takes care of the feedback on $N S(t)$. It is clear that a pure rule-based system is not possible. Especially the last point is complicated. It has to be explored further. But, hopefully, the insensitivity of the system for changes in the total amount of CBDC in the economy is helpful here. The backbone of the rules is the linking of the account balances to $D(t)$.

The debate on rules versus discretion with respect to monetary policy is a classical one. People agree that a rule-based system has advantages. It is attractive that everybody knows the rules and can act accordingly. That it is not necessary for the different actors to anticipate on possible changes and for the $\mathrm{CB}$ to anticipate on these 
anticipations. See e.g. Stokey (2002) for model analyses illustrating how discretion with respect to the policy adds to unnecessary volatility. Rules that have been proposed are e.g. the $k$-percent rule of Friedman (increase the amount of money each year with $k \%$ ) (see Friedman 1960) and the Taylor rule (relating the interest to pay on base money to the differences of actual inflation and norm inflation and actual growth and norm growth) (see Taylor 1993). Most rules are inflation oriented. But the performance of the rules is rather poor ${ }^{13}$. There is rather broad acceptance that the developments in the economy are so unpredictable that following fixed rules leads to a too low performance with respect to inflation, stability and economic development in general. We have to relate our proposal to this debate.

\subsection{The role of near-money}

Goodhart and Jensen (2015) argue that the distinction between two schools of monetary economics, the currency school and the banking school is important to understand the debate. The currency school separates money creation and financial intermediation. Payments are in this single currency. The banking school accepts that it is also possible to pay with demand deposits created and guaranteed by banks, possibly on a fractional reserve basis ${ }^{14}$. For the currency school it is essential to have a good way to establish the total amount of money. That is the main way to control the inflation. And, of course, the currency school proponents look for some general rule to determine the amount of money. The banking school is more pragmatic here. People can settle their transactions with money or with demand deposits or with whatever form of "near-money ${ }^{15 "}$. That brings about a variety of tools to influence the financial system and given this variety it is does not make sense to try to stick to fixed rules. The banking school goes for flexibility and discretion. An argument that may also play a role is that discretion gives also much more freedom to the CB. It is not only discretion, but it is their discretion, while rules can be discussed publicly and politically.

\footnotetext{
${ }^{13}$ It has to be noted that rules like that of Taylor are not even intended to be mechanistically applied. They serve rather as benchmark to make the CB monetary policy more transparent and easier to communicate. See also Levin (2014).

${ }^{14}$ This discussion goes back to Ricardo and his proposals for the establishment of a National Bank.

${ }^{15}$ Near money consists of highly liquid assets which are not cash, but can easily be converted into cash.
} 
The banking school is main stream, but since the financial crisis of 2008 there has been a revival of the currency school. People have associated this crisis with the growing complexity of the monetary and financial systems. This complexity has led to a difficult to control growth of the financial sector, and the lack of transparency that came with it has resulted in various ways to abuse the possibilities (Roubini, Mihm 2021). So, there are good reasons to simplify, and one of the possibilities is to separate again money creation and financial intermediation. Goodhart and Jensen (2015) have some sympathy for this separation and see the advantages, but warn that it is difficult to determine a "hard and fast" distinction between money and near-money. The approach developed here belongs to the currency school. We presuppose indeed, that our money, CBDC, is used for all transactions or at least for all payments from households to businesses. The balances are linked to $D(t)$, the total sum of all these payments over the past year. This makes the system less sensitive for changes in the total amount of CBDC, but it is certainly important that using CBDC is by far the most important way to settle transactions. Otherwise, $D(t)$ is getting unstable as proxy of the DP.

Currently the most important forms of near-money are Money Market Funds (MMF) and foreign currency or Bitcoins and other crypto currency. We discuss these below.

1. MMF. The body of an MMF is formed by liquid bonds (close to their redemption date). An MMF can be used in the same way as bank deposits. If the payee requires payment in CBDC, the MMF share can be exchanged in CBDC just in time. Some payees may agree with direct payment in MMF. It is not to expect however, that the yield on liquid bonds is much higher than the yield on CBDC balances $(-\tau$ or $-\sigma$, depending on where it is stalled). And it is not necessary to use this option for security reasons, since CBDC is completely safe. Households are certainly not going to use it for their payments.

2. Foreign currency/bitcoins. Another possibility to deal with a surplus of liquidity (CBDC) is to exchange it for some foreign currency and change it back as soon as necessary. This may be attractive in times that $D(t)$ is not increasing while in other countries (or in the bitcoin world) the purchasing power of the currency remains stable. If the transactions are still settled with CBDC, this does not lead to a decrease 
of $D(t)$ and $D(t)$ is still a good basis for linking. To guarantee this is essential for our system. It is helpful here to have government and semi-government organizations requiring payment in CBDC. Maybe it is possible to determine that all transactions that have to be accountable are in CBDC.

\subsection{Extreme disturbances}

So, the backbone of the system, the taxed linking to $D(t)$ is rather robust. It works in all more or less normal circumstances, also if $D(\cdot)$ decreases temporarily. In exceptional circumstances, however, like the actual Corona crisis, it is necessary to apply discretion. In such cases we have to be aware of the fact that $D(t)$ is in fact an estimate of the future $D(t)$. The link has to be suspended until the economy is back to normal.

\subsection{Decision making}

The system is mainly rule-based. The rules are developed by the $\mathrm{CB}$, but have to be agreed upon by government and parliament. This necessitates public and political discussion, first about the structure of the system. In a parallel paper (Van Hee, Wijngaard 2021) we explained how it is possible to migrate the current system into this one. So, it is feasible, but it is certainly a major change. We are not going to reflect on the possible discussions, but we just presuppose a situation where the structure of the system is accepted. The definition of $D(t)$ looks rather a-political. That is different, however, for $\tau, \sigma, \rho$. But it may be helpful here that it is possible to work with a learning period. The same holds for the limit $H$ on the household accounts that are free of liquidity tax. The final values of the parameters could be the result then of a gradual process of convergence. The parameter $S_{N}$ is more dynamic, because it is also related to demographic changes. The $\mathrm{CB}$ has to develop general rules and discuss these publicly. The elements that are most open for discussion are the guidelines with respect to the feedback on $N S(t)$. It may be possible to develop explicit guidelines. But each year, the actual feedback is going to be the result of political decision making with respect to government expenses. Hopefully it is possible to develop bandwidths that are politically acceptable. How wide these bandwidths have to be depends on the 
sensitivity of the monetary performance (stability of purchasing power and of riskfree interest) for changes in the precise feedback. This has to be explored.

\section{The eurozone}

In the previous sections we considered the situation with one currency and one country and government. Is it possible to apply the same approach in the eurozone, with one currency and 19 governments/countries?

If we want to keep this idea of linking the account balances to a macro-economic variable, it has to be one and the same variable, a proxy $D(t)$ for the domestic product of the whole eurozone. There is a considerable heterogeneity within the eurozone, so, price levels may vary significantly from country to country. But as long as the price changes correspond, the automatic inflation correction through the linking works well. The parameters $\tau, \rho, \sigma$ are eurozone-wide. There is no option to make these country dependent. But that is different for the parameter $S_{N}$ and the feedback on $N S(t)$, using e.g. the parameters $S_{L}$ and $S_{U}$ Here we have the possibility to make the system country dependent. Let $E_{i}(t), C B_{i}(t), S_{i}(t), N S_{i}(t), G_{i}(t), C G_{i}(t), N G_{i}(t)$ be the country specific forms of the corresponding variables, defined in section 5 . We assume that the liquidity tax and the interest paid by banks for loans of the $\mathrm{CB}$ are transferred to the country of the account owner. We need to organize the feedback of $\Delta N G(t)$, so of all $\Delta N G_{i}(t)$ on $N S(t)$, so on all $N S_{i}(t)$. How can we translate, for instance, the feedback suggested in section 5 to this case with more countries? Refer to equations $(9 \mathrm{a} / \mathrm{b})$.

Most straightforward is to choose (for all $i$ ):

$$
\begin{aligned}
& \Delta N G_{i}(t) \leq \gamma \cdot\left(N S_{i}(t)-S_{L i}\right) \text { if } N S_{i}(t)<S_{L i} \\
& \Delta N G_{i}(t) \geq \gamma \cdot\left(N S_{i}(t)-S_{U i}\right) \text { if } N S_{i}(t)>S_{U i}
\end{aligned}
$$

It is possible of course to choose as well different control parameters $\gamma_{i}$ for the different countries. It is not necessary to let the guidelines for government budgets be 
based on this kind of rules. But these rules illustrate well how the individual characteristics of the countries with respect to saving, leading to differences in $S_{N i}$, can be taken into account. It is interesting to compare this with the guidelines that are used currently: a government deficit should not be higher than $60 \%$ of the DP.

\section{Conclusions and suggestions for further research}

This paper fits in the general movement of exploring the possibilities of Central Bank Digital Currency (CBDC) in our monetary systems. The weaknesses of the current systems became clear during the financial crisis of 2008 and its aftermath. These weaknesses are also connected with the two-tiered character of the system (base money and claims on base money): we use almost only bank money, claims on base money, while we are not very interested in the use of cash, the only form of base money accessible to us. It is widely agreed upon that it is time to widen the role of base money (or CBDC). The main stream is to fit this into the current system, so to have digital cash next to physical cash without changing the two tiered character of the system. We propose to go a big step further and make the system one-tiered, skip the use of physical cash and have CBDC as our primary form of money, the only legal tender ${ }^{16}$. That leads to a situation where the $\mathrm{CB}$ creates the money and the main role of the banks is to intermediate between lenders and borrowers.

The basis for such a new system, the payment system, is described in Van Hee and Wijngaard (2021). The main elements are sketched in section 2 of this paper. The rest of this paper is devoted to the exploration of the possibilities that such a change gives for the design of the monetary policy. An overview of the monetary tools that are available is given in section 3. In the sections 4 to 7 the tools are used to design one specific monetary policy. The first step is to link the account balances to a proxy of the DP. This is described in section 4. It makes the monetary system insensitive for price changes and conserves the purchasing power of the economic actors. The second step, described in section 5, is to allow that the government can borrow freely from

\footnotetext{
${ }^{16}$ In Van Hee and Wijngaard (2019) we discussed how ambivalent and dysfunctional such a marginal introduction of CBDC is.
} 
the CB. This brings our proposal rather close to the Modern Monetary Theory (MMT). Bonds are not any longer necessary to finance the deficits of the government and not any longer available for the public as a secure form of saving. Instead of that we introduce the possibility to open a savings account with the $\mathrm{CB}$ that is relatively attractive. A too high total balance on these savings accounts can be used as a signal that there is too much CBDC in the economy and may lead to guidelines to restrict the government expenses. A high total amount of CBDC borrowed by the banks can be used as signal that there is too less CBDC in the economy. The two steps, described in section 4 and 5, lead to a monetary system with automatic inflation control and stability with respect to credit possibilities, savings possibilities and risk-free interest rate. The monetary policy is rule-based. The limits of this rule-based character of the policy are discussed in section 6 . In the sections 4 to 6 , we assume that there is one government with one $\mathrm{CB}$, whereas in section 7 we explore the consequences of having more governments with one $\mathrm{CB}$, like in the eurozone.

Looking at these results, we may state that the monetary policy that is developed is sufficiently attractive to warrant further consideration. It shows that the possibilities resulting from a switch to a CBDC based system are indispensable. Further research is necessary of course, to work out the designed monetary policy in more detail, but also to explore alternative policies.

We are not going to formulate a complete list of future research issues, however, because it starts anyway with the question of how to convince the community of bankers and monetary economists that the current system may have failed and that we have to consider a switch to a CBDC based system with as main role for the banks to intermediate between lenders and borrowers. 


\section{Appendix 1 The construction of a suitable DP-proxy.}

We start with a somewhat alternative definition of the DP, $Y$. A definition that is close to the definitions normally in use, but that makes it easy to derive a simple approximation, $D(t)$ that can be monitored throughout the whole year. See figure 1.1.

Figure 1.1. Constructing a simplified version of the DP

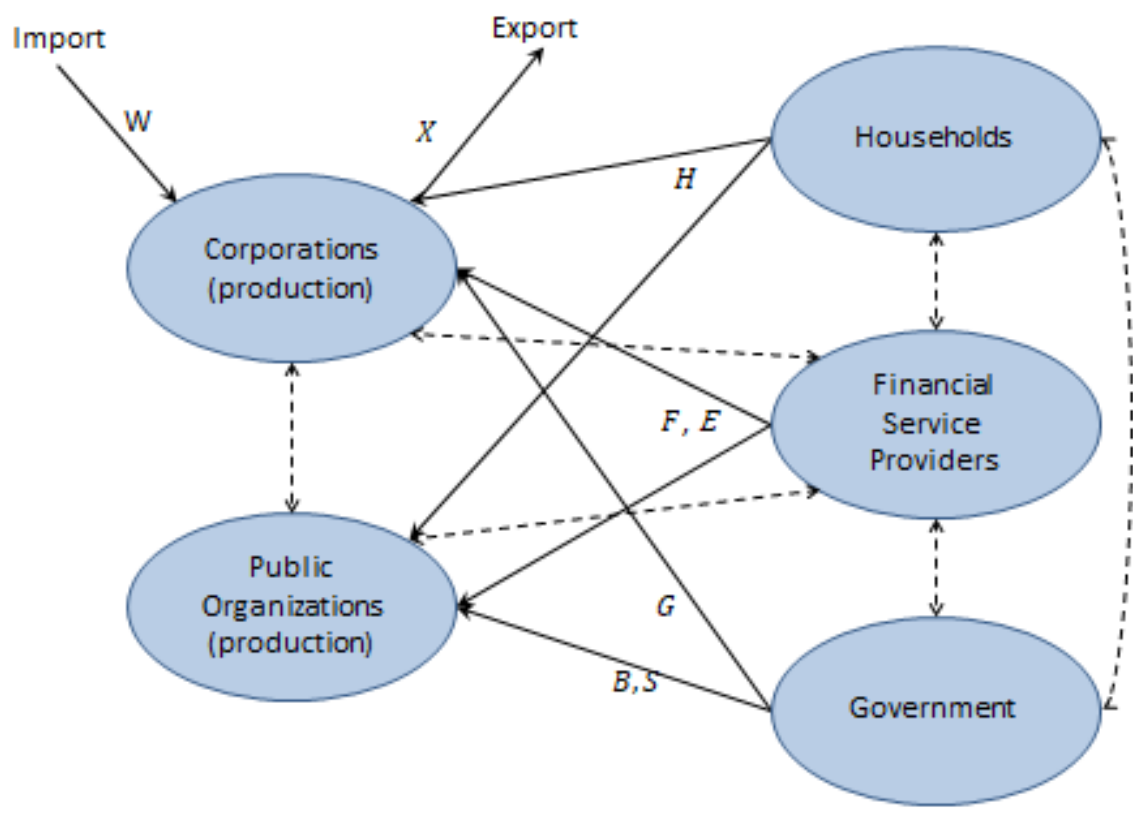

Source: authors' own elaboration

The left hand side of the figure gives the producing organizations, the right hand the consuming organizations. The consuming organizations are Households, Financial Service Providers and Government, the producing organizations are (private) corporations and producing public organizations. The producing public organizations are for instance schools, hospitals, departments for the maintenance of roads and bridges, waterworks and sewerage, housing, etc. So, the government is split into a productive part and a non-productive part. In the non-productive part we find for 
instance: general direction (central and local), tax offices, etcetera. The precise distinction between productive and non-productive is not elaborated here, but is an important step in the detailed design of the DP.

Only the drawn arrows are included in the DP. These stand for expenses from consumers to producers. So, the expenses between producing organizations are not counted. Production is only counted when it is consumed.

All household expenses to producing organizations, $H$, are part of the DP. So, buying a house is also included. Direct expenses for health care are also included. The payments for health care that are made on behalf of insured households are included in $E$. Other insurances are treated in the same way. So, the payments made by a fire insurance company to a building company, for an insured household are included in $E$. The expenses of Financial Service Providers that are necessary to build and maintain their own organization (the operational costs) are included in $F$. The insurance premiums of households are included in the dashed arrow from Households to Financial Service Providers. Insurance premiums of corporations and (producing) public organizations and payments to these organizations made by financial service providers because of that are represented by dashed arrows from and to Financial Service Providers and are not included in the DP. The intermediating role of the Financial Service Providers has no direct effect on the DP ${ }^{17}$. Payments for financial products are anyway excluded from the calculation of the DP.

The expenses for the own organization (the operational costs) of the (nonproductive) government are included in $G$. Subsidies for services for households are included in $S$. The other contributions from the government to public organizations are included in $B$. The precise split between productive and non-productive government is important here. For instance the household contribution for water and sewerage. Whether that is modelled as a tax paid to a tax office or as a service contribution directly paid to the producing organization depends on the precise split between government and producing public organizations.

\footnotetext{
${ }^{17}$ This is a bit awkward. The services of someone who helps you to organize your garden are included in the DP, while the services of someone who helps you to organize your finance are not included. This is suggested for pragmatic reasons. It is important that the expenses for the financial product are not included and it is not always easy to distinguish the expenses for the service and the expenses for the financial product.
} 
Finally we have to include import $W$ and export $X$. So the DP is defined as:

$Y=H+E+F+G+S+B+X-W$

To be able to monitor the DP directly from the payments that are made, we have to replace expenses by payments. So, we define $H(t)$ as the payments by households in the past year, as monitored on day $t$. The same for the other elements of the DP. This leads to the following approximation of the DP:

$Y(t)=H(t)+E(t)+F(t)+G(t)+S(t)+B(t)+X(t)-W(t)$

These variables are available for the $\mathrm{CB}$ throughout the year, if the payments are labelled sufficiently precise. We could use $D(t)=Y(t)$ then. There may be irregularities, however, in $Y(t)$. For instance because the government does not always make certain important payments at the same date. So, instead of using $Y(t)$ it may be better to use an exponentially smoothed average: $\hat{Y}(t)=\alpha \cdot Y(t)+(1-\alpha)$. $\hat{Y}(t-1)$. Another option is to skip $B(t)$ and choose the following approximation:

$D(t)=Y^{\prime}(t)=H(t)+E(t)+F(t)+G(t)+S(t)+X(t)-W(t)$

Or even

$D(t)=Y^{\prime \prime}(t)=H(t)+X(t)-W(t)$.

And $Y^{\prime}(t)$ and $Y^{\prime \prime}(t)$ can also be smoothed of course.

Instead of $Y(t)$, it is also possible, of course, to use $c \cdot Y(t)$. That is completely equivalent. This makes it possible to switch smoothly from one approximation to another. Suppose at day $t$ we want to switch from $Y(t)$ to $Y^{\prime}(t)$. Then we define $c:=$ $Y(t) / Y^{\prime}(t)$ and we continue with $c \cdot Y^{\prime}(t)$. Such a switch may be useful if there are some structural changes in the structure of the government and the way the productive government organizations are paid for. Consider for instance the possibility that it is 
decided that from a certain date onwards, all healthcare is completely free. That may result in some instability of the payments for healthcare. It may be better therefore to exclude healthcare for some time from $D(t)$ and include it again as soon as the situation has stabilized.

We are not going to give one final choice for how to define $D(t)$. The different options have to be explored: their stability, their quality as approximation of $Y(t)$ and the complexity of the labelling that is necessary. We assume here that there is a reasonable possibility.

\section{Labelling}

Transaction labelling is necessary to be able to estimate the components of the DP-proxy that is actually used and of potential alternatives. This seems to be a heavy burden, but we have already such a labeling for the execution of the VAT and the payment industry is obliged to monitor all transactions in order to prevent illegal activities, among others white washing.

- Labeling must be easy to do: Anyway, the sender and the receiver should be part of it, as well as their BIC codes. Further it should be close to the existing VAT codes.

- The system must keep fingerprints of all transactions in order to verify payments.

- Everybody should record its own transaction details in order to be able to prove the legality of the payments using the fingerprints in the system. 


\section{Appendix 2: Price instability}

In the monetary system developed, the amount of money is designed to follow the prices. The prices are ideally exogenous. But in reality there may also be an effect the other way around. Price setting is a matter of individual decisions, but maybe price increases are easier accepted if people know that the average price increases are compensated by more money. In that case the prices are partly endogenous. To explore this we consider the situation with a constant real domestic product. Only the price level is changing and we are going to investigate how the DP linking that we propose in section 4 influences the price level.

Let $p(t)$ be the price level in period t. Assume that $p(0)=1$ and that the nominal domestic product in period 0 is equal to 1 . So, the nominal domestic product in period $t$ is equal to $p(t)$. The price level is assumed to develop according to the following mechanism:

$\ln p(t)=\ln p(t-1)+s(t)+\alpha(\ln m(t)-\ln m(t-1)$

with $m(t)$ the amount of money during period $t$ and $s(t)$ is (independently) uniformly distributed on $[-b,+b]$. If the amount of money has no influence, $\alpha=0$. If the amount of money is fully reflected in the price level, $\alpha=1$. We combine this with the assumption that the real domestic product remains constant, 1. For sake of convenience we assume that there are 10 periods per year. Linking the account balances to the domestic product implies:

$m(t)=m(0) \cdot\left\{\sum_{1}^{10} p(t-i) \cdot 1\right\} / 10$

So, the balance of an account has grown with a factor $m(t)$ while the prices have grown with a factor $p(t)$. That means that the purchasing power has grown with a factor $m(t) / p(t)$. Because of the delay due to the moving average in formula (2.2), the purchasing power is not completely constant. It is interesting to check now how the prices and the purchasing power develop. 
Figures 2.1 gives characteristic results (some realization of the $s(\cdot)$ ) for the case with $b=0.01$ and $\alpha=0.2$. Note that the standard deviation of the $\sum_{1}^{10} s_{t-i}$ is about equal to 0.02 . Such a price level change in a year is considerable indeed. Next to the price level as it develops with influence of the amount of money, we give the price level if there is no influence of the amount of money $(\alpha=0)$.

Figure 2.1: The case $b=0.01$ and $\alpha=0.2$

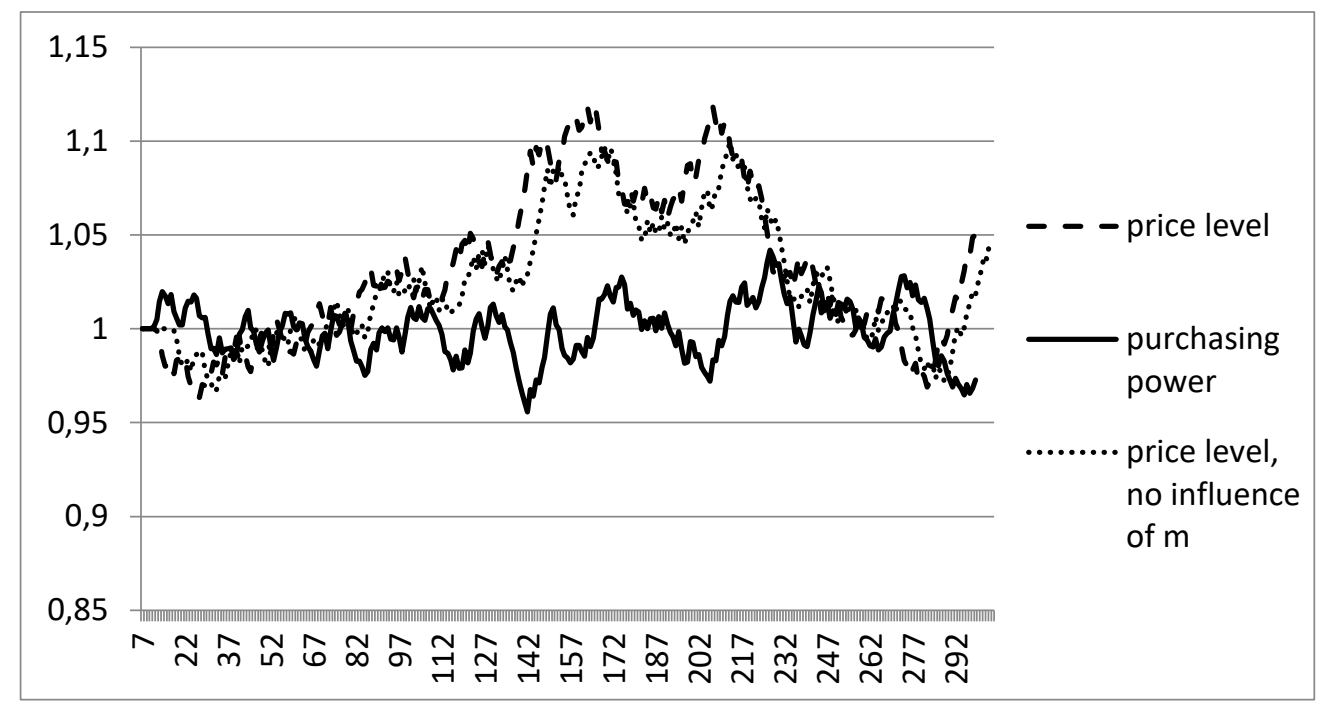

Source: authors' own elaboration

We see how the price level variations are aggravated indeed by the mechanism (1.1). But also that the effect is relatively small for $\alpha=0.2$. And the stability of the purchasing power is not damaged by it. 


\section{Jacob WIJNGAARD, Kees VAN HEE}

\section{Bibliography}

Admati A., Hellwig M. (2013), The Bankers New Clothes, Princeton University Press, New York.

Bordo M.D., Levin A.T. (2017), Central Bank Digital Currency and the Future of Monetary Policy, NBER Working Paper Series 23711.

Buiter W.H. (2009), Negative Nominal Interest Rates. Three Ways to Overcome the Zero Lower Bound, "The North American Journal of Economics and Finance", vol. 20 no. 3, pp. 213-238.

Dyson B., Hodgson G., Van Lerven F. (2016), A Response to Critiques of 'Full Reserve Banking', "Cambridge Journal of Economics", vol. 40, pp. 1351-1361.

ECB (2020), Report on a Digital Euro,

https://www.ecb.europa.eu/pub/pdf/other/Report_on_a_digital_euro 4d7268b458.en.pdf [01.09.2021].

Fontana G., Sawyer M. (2016), Full Reserve Banking. More 'Cranks' than 'Brave Heretics', "Cambridge Journal of Economics", vol. 40 no. 5, pp. 1333-1350.

Friedman M. (1960), A Program for Monetary Stability, Fordham University Press, New York.

Goodhart Ch.A.E., Jensen M.A. (2015), A Commentary on Patrizio Lainà's 'Proposals for Full Reserve Banking: A Historical Survey from David Ricardo to Martin Wolf', "Economic Thought", vol. 4 no. 20, pp. $20-31$

Van Hee K., Wijngaard J. (2019), All Attention to Debt Stands in the Way of Improving Money, "ESB", vol. 104, pp. 251-253.

Van Hee K., Wijngaard J. (2021), A new digital currency system, :Central European Review of Economics and Management", vol. 5 no. 4, pp. 33-60.

Huber J. (2017), Sovereign Money. Beyond Reserve Banking, Palgrave, Cham.

Jackson A., Dyson B. (2012), Modernising Money. Why Our Monetary System Is Broken and How It Can Be Fixed, Positive Money, London.

Kamstra M., Shiller R. (2008), The Case for Trills. Giving Canadians and Their Pension Funds a Stake in the Wealth of the Nation, "C.D. Howe Institute Commentary", no. 271, https://www.cdhowe.org/sites/default/files/attachments/research_papers/mixed//commentary_271.pdf [01.09.2021].

Kelton S. (2020), The Deficit Myth. Modern Monetary Theory and How to Build a Better Economy, John Murray, London.

Levin A. (2014), The Design and Communication of Systematic Monetary Policy Strategies, "Journal of Economic Dynamics and Control", vol. 49(C), pp. 52-69.

Piketty T. (2014), Capital in the Twenty-First Century, Harvard University Press, Cambridge MA.

Roubini N., Mihm S. (2010), Crisis Economics. A Crash Course in the Future of Finance, Penguin Books, London. 
DESIGN OF A RULE-BASED MONETARY POLICY IN A CENTRAL BANK ...

Ryan-Collins J., Greenham T., Werner R., Jackson A. (2011), Where Does Money Come from, New Economics Foundation, London.

Stokey N.L. (2002), 'Rules vs Discretion' after Twenty-Five Years, "NBER Macroeconomics Annual”, vol. 17.

Sveriges Riksbank (2017), The Riksbank's e-krona project: Report 1, https://www.riksbank.se/globalassets/media/rapporter/ekrona/2017/rapport_ekrona_uppdaterad_170920_eng.pdf [01.09.2021].

Taylor J.B. (1993), Discretion versus Policy Rules in Practice, "Carnegie-Rochester Conference Series on Public Policy", vol. 39, pp. 195-214. 